\title{
Nesfatin-1 suppresses fish reproductive axis and gonadal steroidogenesis
}

\author{
Jithine Jayakumar Rajeswari and Suraj Unniappan \\ Laboratory of Integrative Neuroendocrinology, Department of Veterinary Biomedical Sciences, Western College of \\ Veterinary Medicine, University of Saskatchewan, Canada
}

Correspondence should be addressed to S Unniappan; Email: suraj.unniappan@usask.ca

\begin{abstract}
Nesfatin-1 is a naturally occurring orphan ligand in fish and mammals. Research in our lab resulted in the identification of an inhibitory role for nesfatin-1 on pituitary hormones (goldfish) and oocyte maturation (zebrafish). The present study is an extension of these original findings and aimed to determine whether nesfatin-1 has any additional effects on HPG genes in male and female goldfish. We found that a single i.p. injection of synthetic nesfatin-1 (50 ng/g body weight) downregulated the expression of salmon gonadotropin-releasing hormone (sgnrh), chicken gnrh-II (cgnrh-II), kisspeptin receptor (gpr54a) and brain aromatase (cyp19a1b) mRNAs in the hypothalamus of both male and female goldfish at $\mathbf{1 5}$ min post-administration. In the pituitary of both males and females, nesfatin-1 reduced luteinizing hormone beta $(I h \beta)$ and follicle stimulating hormone beta ( fsh $\beta$ ) mRNA expression at 60 min and gpr54a mRNA at $15 \mathrm{~min}$. Similarly, the gonadotropin receptors $/ \mathrm{hr}$ and fshr were downregulated in the gonads. Meanwhile, gonadotropin inhibiting hormone (gnih), gnih receptor, kisspeptin 1 (kiss1) and gpr54a mRNA expression in the gonads were increased post-nesfatin-1 treatment. Nesfatin-1 negatively influences the star, cytochrome P450 family 11 subfamily A member 1 , anti-mullerian hormone and aromatase mRNAs. In agreement with these results, nesfatin-1 reduced plasma estradiol and testosterone in female and male goldfish circulation at $\mathbf{6 0}$ min post-injection. The information generated through this research further solidified nesfatin-1 as an inhibitor of reproductive hormones in fish. Targeting nesfatin-1 and related peptides could yield beneficial effects in fish reproduction and aquaculture.

Reproduction (2020) 160 445-454
\end{abstract}

\section{Introduction}

Vertebrate reproduction is heavily regulated by hormones primarily produced from the hypothalamopituitary-gonadal (HPG) axis (Unniappan 2010). Along with the HPG hormones and releasing factors, multiple non-HPG hormones and neuropeptides are also involved in the regulation of reproduction in vertebrates. As reproduction is a highly energy-dependent process, food supply and adequate body energy stores are crucial factors for the proper action of reproductive hormones and reproductive success (Schneider 2004, Scaramuzzi et al. 2006, Hill et al. 2008, Evans \& Anderson 2012). The interplay between energy status and reproduction is primarily controlled by the endocrine regulatory centers in the brain, mainly through neuroendocrine signals. It was reported that many metabolic hormones can alter the release of the gonadotropins from the anterior pituitary either by directly acting on the pituitary or indirectly through its actions on the neuroendocrine centers of the brain, which includes the hypothalamus (Gonzalez et al. 2012a). There are many hormone-like factors that are emerging as regulators of both metabolism and reproduction. One such example is nesfatin-1, encoded in the precursor nucleobindin-2 (Nucb2).

Nucb2 is a calcium and DNA binding precursor peptide that is proposed to be cleaved by prohormone convertases (PCs) to produce three shorter peptides, nesfatin-1, 2 and 3 (Oh-l et al. 2006). Of these, only nesfatin- 1 was found to have an anorexigenic action (Oh-I et al. 2006). Multiple studies reported the importance of nesfatin-1 in energy homeostasis in mammals (Oh-I et al. 2006, Gonzalez et al. 2012b, Wernecke et al. 2014, Mortazavi et al. 2015). Nucb2 mRNA and protein increases during pubertal transition, and there is an increase in LH release in female rats post-nesfatin-1 administration. Morpholino-mediated gene knockdown resulted in a reduction in circulating LH levels in female pubertal rats (García-Galiano et al. 2010). The same year, Gonzalez and colleagues reported a significant decrease in food intake in goldfish after either i.p. (50 ng/g body weight) or intracerebroventricular (ICV, $5 \mathrm{ng} / \mathrm{g}$ body weight) injection of nesfatin-1 (Gonzalez et al. 2010). Studies in zebrafish suggest that nutrient status modulates the expression of nucb2 in fish (Hatef et al. 2015). There is a decrease in nucb2/nesfatin-1 in the brain and gut of zebrafish fasted for 7 days, which provides 
additional support for its anorexigenic property. The first evidence for the regulatory role of Nucb2/nesfatin-1 on reproduction in a non-mammalian vertebrate was reported in goldfish (Gonzalez et al. 2012a). I.p. injection of goldfish nesfatin-1 significantly reduced the expression of gnrh, Ih and $f s h$, and serum Lh in goldfish. In addition, incubation of ovarian follicles with nesfatin- 1 significantly reduced germinal vesicle breakdown and maturation of oocyte in zebrafish. Nesfatin-1 appears to be another linker of energy homeostasis and reproduction in fish. However, studies in female rainbow trout did not show any significant change in circulating nesfatin-1 during long-term fasting, and no positive correlation between circulating nesfatin- 1 levels and seasonal maturation was found (Caldwell et al. 2014). This suggests that nesfatin-1 possibly has species- and sex-specific regulatory effects on reproduction and warrants further research on nesfatin-1 and reproduction.

While most of the aforementioned research in mammals and fish focused on females, Gao and colleagues reported a reduction in the expression of many mRNAs and proteins involved in the reproductive axis of adult male rats post-nesfatin- 1 administration (Gao et al. 2016). This includes Gnrh, Kiss 1, Lh $\beta$, Fsh $\beta$ and Star, 33-hydroxysteroid dehydrogenase $(3 \beta$-hsd), $17 \beta$-hydroxysteroid dehydrogenase $(17 \beta$-hsd), and cytochrome P450 cleavage ( 450 scc), mRNA transcripts and serum levels of $\mathrm{LH}, \mathrm{FSH}$ and testosterone. This finding further suggests a sex-specific role for nesfatin-1 on reproduction in vertebrates. We hypothesized that nesfatin-1 suppresses the expression of HPG and nonHPG genes involved in reproduction and circulating levels of gonadal hormones in a sex-specific manner in fish. This research is a logical extension of our own studies that discovered a role for nesfatin-1 in fish reproduction (Gonzalez et al. 2012a). It determined how exogenously administered nesfatin- 1 influences critical genes involved in goldfish reproduction (HPG and non-HPG axis regulators of reproduction). Further, we tested whether there are any effects for nesfatin- 1 on gonadal steroids in goldfish circulation.

\section{Materials and methods}

\section{Animals}

Mature male and female goldfish (Carassius auratus) of the common variety, $20 \pm 3 \mathrm{~g}$, were obtained from a local vendor through the institutional animal order desk. Fish were housed in freshwater aquaria (60 L capacity) at $23 \pm 2{ }^{\circ} \mathrm{C}$, under a simulated $12 \mathrm{~h}$ light: $12 \mathrm{~h}$ darkness photoperiod (lights on at $0700 \mathrm{~h})$. Once daily, at a scheduled feeding time (1100 h), fish were fed with commercial slow sinking pellets (Aqueon, Franklin, USA). All studies using fish complied with the Canadian Council for Animal Care regulations and were approved by the Animal Research Ethics Board (Animal Use Protocol \# 2012-0082) of the University of Saskatchewan.

\section{Experimental design and sampling}

All experiments were completed between late spring and early summer (May-June) when goldfish were reproductively active. Male and female goldfish were randomly selected (weight matched) and were acclimated to $10 \mathrm{~L}$ experimental aquaria ( $n=2$ /aquaria), maintained in a constantly aerated, continuous flow, temperature $\left(23 \pm 2{ }^{\circ} \mathrm{C}\right)$ controlled water current system. The objective of this research was to further determine the effects of nesfatin-1 on reproduction. Therefore, for the in vivo injection study, we used the same dose of nesfatin- 1 and timepoints that were previously found effective in our own research (Gonzalez et al. 2012a). Briefly, male and female goldfish were anesthetized by using tricaine methanesulfonate-222 (TMS, 0.5\%, Syndel Laboratories, BC, Canada) and injected intraperitoneally with $100 \mu \mathrm{L}$ of saline containing $(50 \mathrm{ng} / \mathrm{g}$ body weight) goldfish synthetic nesfatin-1. The goldfish nesfatin-1 (1-82) (gfnesfatin-1; VPISIDKTKVKLPEETVKES PQNVDTGLHYDRYLREVIDFLEKDQHFREKLHNTDMEDIK QGKLAKELDFVSHHVRTKLDEL) was custom synthesized (Genscript, Piscataway, NJ, USA) and the purity (>95\%) of the synthetic peptide was confirmed by mass spectrometry and MALDI-TOF (Gonzalez et al. 2010). Although the circulating levels of nesfatin-1 varies due to physiological conditions, the dose used here is likely supraphysiological based on the serum NUCB2/nesfatin-1 concentrations reported in goldfish (Gonzalez et al. 2010). The control group was injected with sterile saline $(0.9 \% \mathrm{NaCl} ; 100 \mu \mathrm{L})$. Six male and six female fish from each of the groups (control and treatment) were anesthetized and euthanized at $15 \mathrm{~min}$ and $60 \mathrm{~min}$ postnesfatin-1 administration. Tissues including hypothalamus, pituitary and gonads were collected and flash-frozen immediately in liquid nitrogen and stored at $-80^{\circ} \mathrm{C}$ until further processing. Blood was collected from caudal vein and serum was separated and stored at $-20^{\circ} \mathrm{C}$ for ELISA.

\section{$R T$-qPCR based $m R N A$ expression analysis}

Total RNA extraction and cDNA synthesis were carried out as previously described (Rajeswari et al. 2019). Briefly, total RNA was extracted from tissue samples from goldfish including hypothalamus, pituitary and gonads using RiboZol RNA isolation reagent (aMReSCO, Canada) followed by DNase I (Thermo Fisher Scientific) treatment. Optical density (OD) absorption ratio (OD $260 \mathrm{~nm} / \mathrm{OD} 280 \mathrm{~nm}$ ) was measured using a Nanodrop 2000 (Thermo Fisher Scientific) for determining the quantity and quality of RNA extracted. iScript cDNA synthesis kit (Bio-Rad) was used for cDNA synthesis. Quantitative PCR (qPCR) was used as described earlier (Blanco et al. 2017, Rajeswari et al. 2019) for mRNA expression analysis employing the Universal SYBR Green Master Mix (Bio-Rad) and the CFX Connect Real-Time PCR Detection System (Bio-Rad). Primer validation and efficiency of primers were confirmed for each primer set as described earlier (Gonzalez et al. 2012a). Genes quantified in this study were all previously documented to have a role in goldfish reproduction. Details of primers and primerspecific annealing temperatures used are provided in Table 1. Rest of the qPCR conditions are as follows: denaturation/ polymerase activation: $95^{\circ} \mathrm{C}(3 \mathrm{~min})$; followed by 35 cycles 
Table 1 List of primers and annealing temperatures used in PCR.

\begin{tabular}{|c|c|c|c|c|}
\hline \multirow[b]{2}{*}{ Gene } & \multirow[b]{2}{*}{ Accession no. } & \multicolumn{2}{|c|}{ Primer sequence $\left(5^{\prime}-3^{\prime}\right)$} & \multirow{2}{*}{$\begin{array}{c}\text { Annealing } \\
\text { temperature }\left({ }^{\circ} \mathrm{C}\right)\end{array}$} \\
\hline & & Forward & Reverse & \\
\hline $18 S r R N A$ & FJ710819.1 & GGATGCCСTTAACTGGGTGT & CTAGCGGCGCAATACGAATG & 60 \\
\hline$\beta$-actin & AF079831.1 & CTACTGGTATTGTGATGGACT & TCCAGACAGAGTATTTGCGCT & 60 \\
\hline sgnrh & AB020243.1 & GGATGATGGATTCTGGTGATG & CTATGTGTATCGGTGAAAGC & 59 \\
\hline cgnrh-II & U30386.1 & TACGATTCCTCAGAGGTTTCAG & CATCCAGCAGTATTGTCTTCAG & 59 \\
\hline kiss1 & FJ465138.1 & GACTCCAAGCAGCACTATC & CCCAAACGGGTTGTAGTT & 61 \\
\hline gpr54a & FJ465139.1 & CTGGTGCСССTTTTCTTCTC & GGGTAGAGGGTAGCAGTGAA & 61 \\
\hline gnih & AB078976.1 & СТСССАССАТССТGСGАСТT & CTTTGCGGTAGGGTGGCTGA & 57 \\
\hline gnihr & JN204438.1 & CCAGCGTCAАСССТАTTATC & AGCAGCCGTATTCAAAGG & 59 \\
\hline Ih $\beta$ & MH536845.1 & GCTTGCCAGACTGTCCTC & GTCAGATGTGTCCATAGTGC & 59 \\
\hline$f_{s h} \beta$ & MH536843.1 & GTTGTTATGGTGATTCTGTTG & ACGGTGATGGAGATATTGG & 60 \\
\hline fshr & HM347775.1 & CGTCCACAATCCTACСТTCG & TGAGAAACGGTGATTAAGCGG & 57 \\
\hline Ihr & HM347776.1 & ССTCTGCATCGGTGTGTATC & TAGACAGATGATTCGCCCGCC & 60 \\
\hline сур11a1 & JQ340311.1 & TACATTGATCCAGACGCCCA & TTAAAGATGCCGTCCCAAGC & 57 \\
\hline cyp19a1a & JN620808.1 & GTGCTCAAGACAATGTGTGC & AAATGAACCCTACCAACCCG & 60 \\
\hline сур 19a1b & AB009335.1 & AGGCGAGCGGGATGTAGAGT & CGTCCGATGTTCAGGATGAGG & 59 \\
\hline StAR & AY877430.1 & ATGGCTGGCAAACTGAGATCGAGA & TCCATGTTATCCACCAGCTCCTCA & 58 \\
\hline$a m h$ & KF640083.1 & TCTCCGAAAGGAGAGGACGA & TTCATCCGСTCTGACTGCTC & 57 \\
\hline ar & AY090897.1 & TGGCTCGAACTTTTCCAAGG & TCTGTGGAAAACTGCGTCTG & 58 \\
\hline er & AY055725.1 & ACAGGTCCAGTGTTGTGTGT & ATGATAGCCGGACGCATAGT & 58 \\
\hline
\end{tabular}

of denaturation: $95^{\circ} \mathrm{C}$ (10 s); and annealing: specific to each gene (30 s) (Table 1). A melting curve analysis was performed at $65^{\circ} \mathrm{C}$ to $95^{\circ} \mathrm{C}(5 \mathrm{~s})$ to confirm a single amplicon or single PCR product generated. Livak method (Livak \& Schmittgen 2001) was used for the qPCR data analysis, and the data were normalized to the housekeeping genes (18s rRNA and $\beta$-actin).

\section{Serum testosterone and estradiol measurement using ELISA}

Serum gonadal steroids were measured using testosterone (human) and estradiol (human) ELISA kits (Eagle Biosciences Inc., USA) previously validated for quantifying goldfish sex steroids by our lab (Bertucci et al. 2016). ELISAs were carried out according to the manufacturer's instructions.

\section{Statistical analysis}

Statistical analysis were performed using Student's $t$-test and the levels of significance were set at $P<0.05$. PRISM version 5 (GraphPad Inc.) was used for generating graphs and statistical analysis. All data are presented as mean + S.E.M.

\section{Results}

\section{Nesfatin-1 administration downregulated the expression of gnrh and kisspeptin and brain aromatase in the hypothalamus of goldfish}

We observed a significant reduction in the expression of salmon growth hormone-releasing hormone (sgnrh) and chicken growth hormone-releasing hormone-Il (cgnrhII) mRNA expression in the hypothalamus of male and female goldfish 15 min post-nesfatin-1 administration (Fig. 1A, B, C, D). A significant reduction in kisspeptin 1 receptor (gpr54a) mRNA expression was found in both male and female treatment groups 15 min postnesfatin-1 administration (Fig. $1 \mathrm{G}$ and H). Similarly, cytochrome P450, family 19, subfamily A, polypeptide 1b (cyp19a1b, also called brain aromatase) mRNAs were attenuated in both male and female treatment groups at $15 \mathrm{~min}$ post-injection (Fig. 1I and J). No significant changes in kisspeptin 1 mRNA expression were observed in the hypothalamus of male and female treatment groups compared to control (Fig. 1E and F). No significant changes in gnih and gnih receptor (gnihr) mRNA expression were detected in the hypothalamus of goldfish post-nesfatin-1 administration (data not shown).

\section{Nesfatin-1 suppressed the expression of the gonadotropin $\beta$ subunits and kisspeptin system in the pituitary of goldfish}

Nesfatin-1 downregulated the expression of $/ h \beta$, fsh $\beta$ mRNA expression in the pituitary of both male and female goldfish groups 60 min post-injection (Fig. 2A, B, C, D). Nesfatin-1 caused a significant decrease in gpr54a mRNA expression in the pituitary of both treatment groups at $15 \mathrm{~min}$ post-injection (Fig. 2G and $\mathrm{H})$. However, there were no significant changes in kiss 1 mRNA expression in male or female treatment groups post-nesfatin-1 administration (Fig. 2E and F).

\section{Nesfatin-1 modulated the expression of gonadotropin receptor and sex steroid receptor $m R N A$ expression in the gonads of goldfish}

In the gonads of both male and female goldfish, we found a reduction in the expression of /h receptor (/hr) mRNA expression at 15 min post-nesfatin-1 administration (Fig. $3 \mathrm{~A}$ and $\mathrm{B}$ ). However, the $f_{s} h$ receptor ( $f_{s h r}$ mRNA 

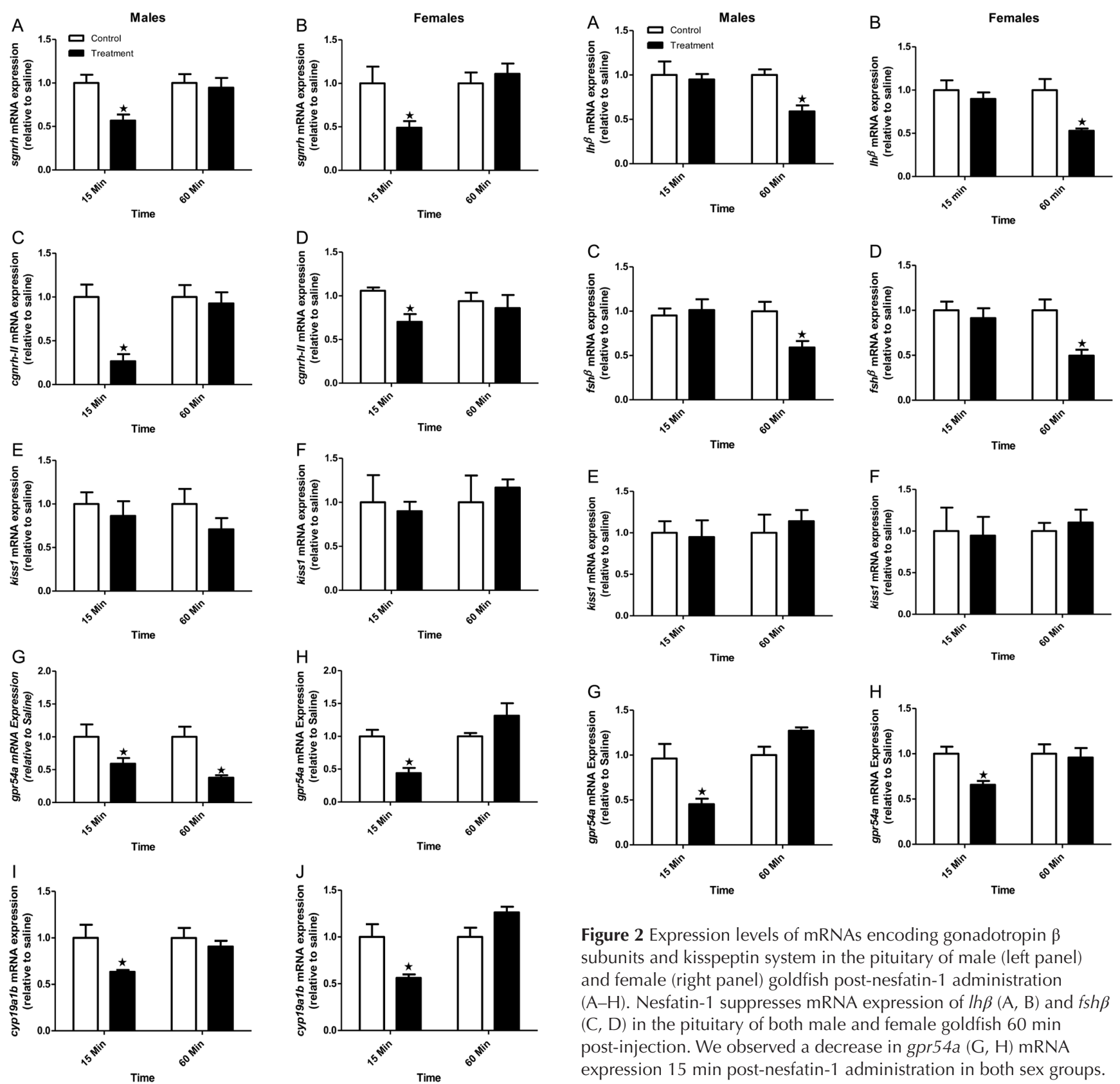

Figure 2 Expression levels of mRNAs encoding gonadotropin $\beta$ subunits and kisspeptin system in the pituitary of male (left panel) and female (right panel) goldfish post-nesfatin-1 administration (A-H). Nesfatin-1 suppresses mRNA expression of $\operatorname{lh} \beta(\mathrm{A}, \mathrm{B})$ and $f_{s h} \beta$ (C, D) in the pituitary of both male and female goldfish $60 \mathrm{~min}$ post-injection. We observed a decrease in $\operatorname{gpr} 54 a(\mathrm{G}, \mathrm{H}) \mathrm{mRNA}$ expression 15 min post-nesfatin-1 administration in both sex groups. However, we did not observe any significant changes in the expression of kiss 1 (E, F) in the pituitary of both sex groups. Data obtained by RT-qPCR are represented as mean + S.E.M. ( $n=6 \mathrm{fish} /$ group). Student's $t$-test was used for statistical analysis, and the level of significance was set at $P<0.05$. Asterisks denote significant differences between control and treated groups. and cyp19a1b (I, J). No significant changes in kiss1a were observed in the brain of goldfish post-nesfatin-1 injection (E,F). Data obtained by RT-qPCR are represented as mean + S.E.M. ( $n=6$ fish/group). Student's $t$-test was used for statistical analysis, and the level of significance was set at $P<0.05$. Asterisks denote significant differences between control and treated groups.

shows a differential expression pattern. In the testis of goldfish, a significant decrease in fshr was observed at 15 min (Fig. 3C) post-injection. In the ovary of goldfish, we found a significant reduction in $f$ shr mRNA

expression only at 60 min post-nesfatin- 1 administration (Fig. 3D). Androgen receptor (ar) mRNA expression was significantly upregulated in the testis (at $15 \mathrm{~min}$ ) and downregulated in the ovary of goldfish (at $15 \mathrm{~min}$ ) post-nesfatin-1 administration (Fig. 3E and F). However, we did not observe any significant changes in estrogen receptor (er) mRNA expression in the gonads of goldfish post-nesfatin- 1 administration (Fig. $3 \mathrm{G}$ and $\mathrm{H}$ ). 

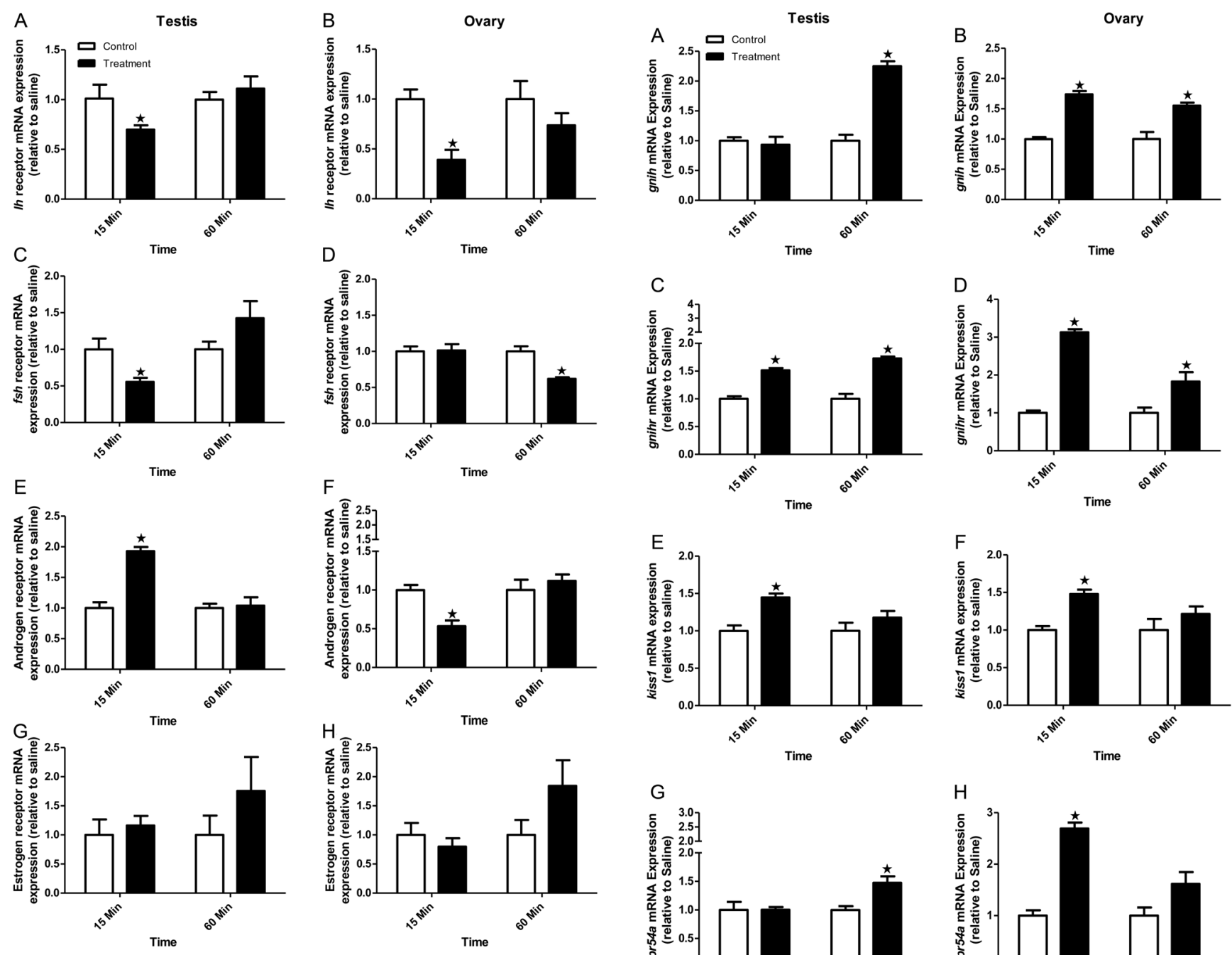

Figure 3 The mRNA expression profile of gonadotropin and sex steroid receptor mRNAs in the testis (left panel) and ovary (right panel) of goldfish post-nesfatin-1 administration (A-H). In the gonads of goldfish, a significant decrease in $\operatorname{lhr}(\mathrm{A}, \mathrm{B})$ and $f s h r(\mathrm{C}, \mathrm{D})$ mRNA expression was observed post-nesfatin-1 administration. In the testis of goldfish, a significant increase in ar mRNA expression was observed at $15 \mathrm{~min}$ post-nesfatin-1 injection (E). However, in the ovary, a significant decrease in ar mRNA expression was observed 15 min post-injection (F). We did not observe any significant changes in the expression of er $(\mathrm{G}, \mathrm{H}) \mathrm{mRNA}$ expression in the gonads of both sex groups postnesfatin-1 injection. Data obtained by RT-qPCR are represented as mean +S.E.M. ( $n=6$ fish/group). Student's $t$-test was used for statistical analysis, and the level of significance was set at $P<0.05$. Asterisks denote significant differences between control and treated groups.

\section{Nesfatin-1 modulated the expression of gnih, gnihr, kiss1 and gpr54a mRNA expression in the gonads of goldfish}

A significant increase in gnih mRNA expression was observed in the testis (only at $60 \mathrm{~min}$ ) and ovary (both 15 and $60 \mathrm{~min}$ ) post-nesfatin-1 injection (Fig. 4A and B). In addition, gnihr mRNA expression was also upregulated
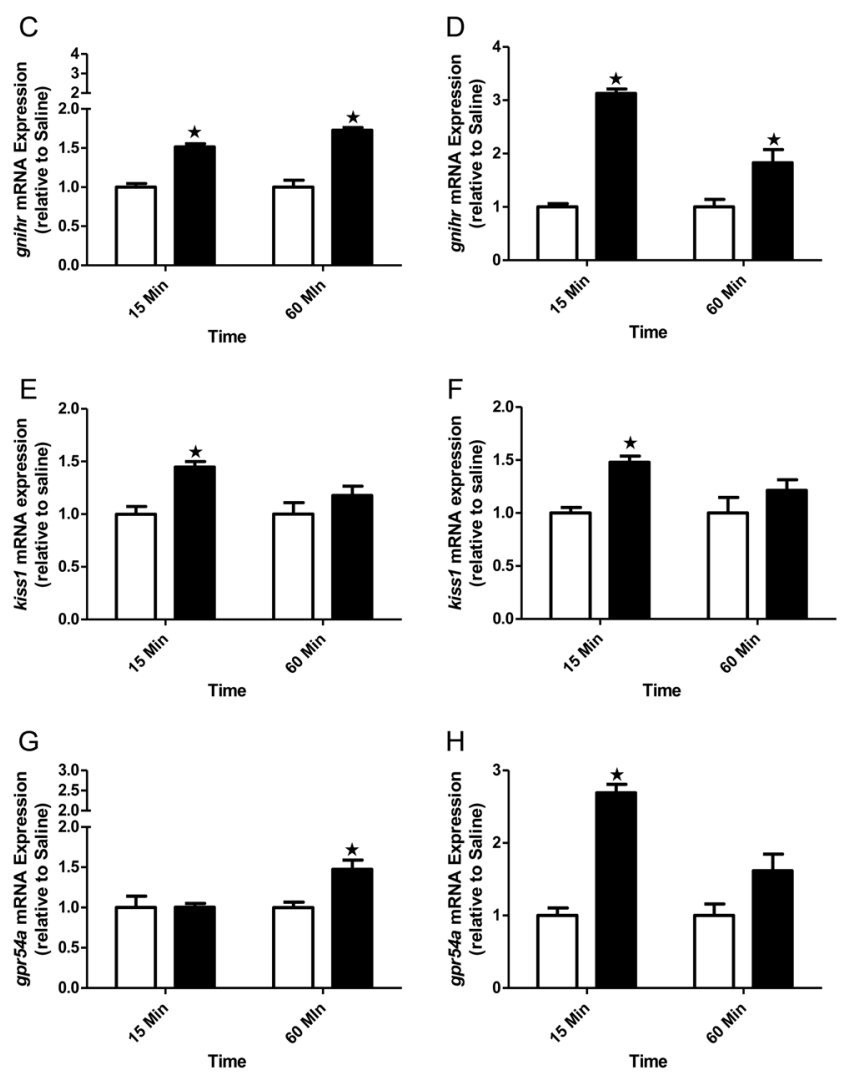

Figure 4 Expression profile of gnih and kisspeptin system mRNA's in the testis (left panel) and ovary (right panel) of goldfish post-nesfatin-1 administration $(\mathrm{A}-\mathrm{H})$. A significant increase in gnih mRNA expression was observed in the testis (only at $15 \mathrm{~min}$ ) (A) and ovary (both 15 and $60 \mathrm{~min}$ ) (B) post-nesfatin-1 administration. Nesfatin-1 elevates the expression of gnihr mRNA expression at both 15- and 60-min time points in the testis and ovary of goldfish (C, D). The mRNA expression of both kisspeptin and gpr54a mRNAs were significantly increased in the gonads of both male and female goldfish (E-H). Data obtained by RT-qPCR are represented as mean +S.E.M. ( $n=6$ fish/group). Student's $t$-test was used for statistical analysis, and the level of significance was set at $P<0.05$. Asterisks denote significant differences between control and treated groups.

at both 15 and 60 min post-nesfatin-1 injection (Fig. 4C and D). We found a significant increase in kiss 1 (Fig. 4E and F) (at $15 \mathrm{~min}$ ) and gpr54a (60 min in male and 15 min in female) (Fig. 4G and $\mathrm{H}$ ) mRNA expression in the gonads of both treatment groups. 

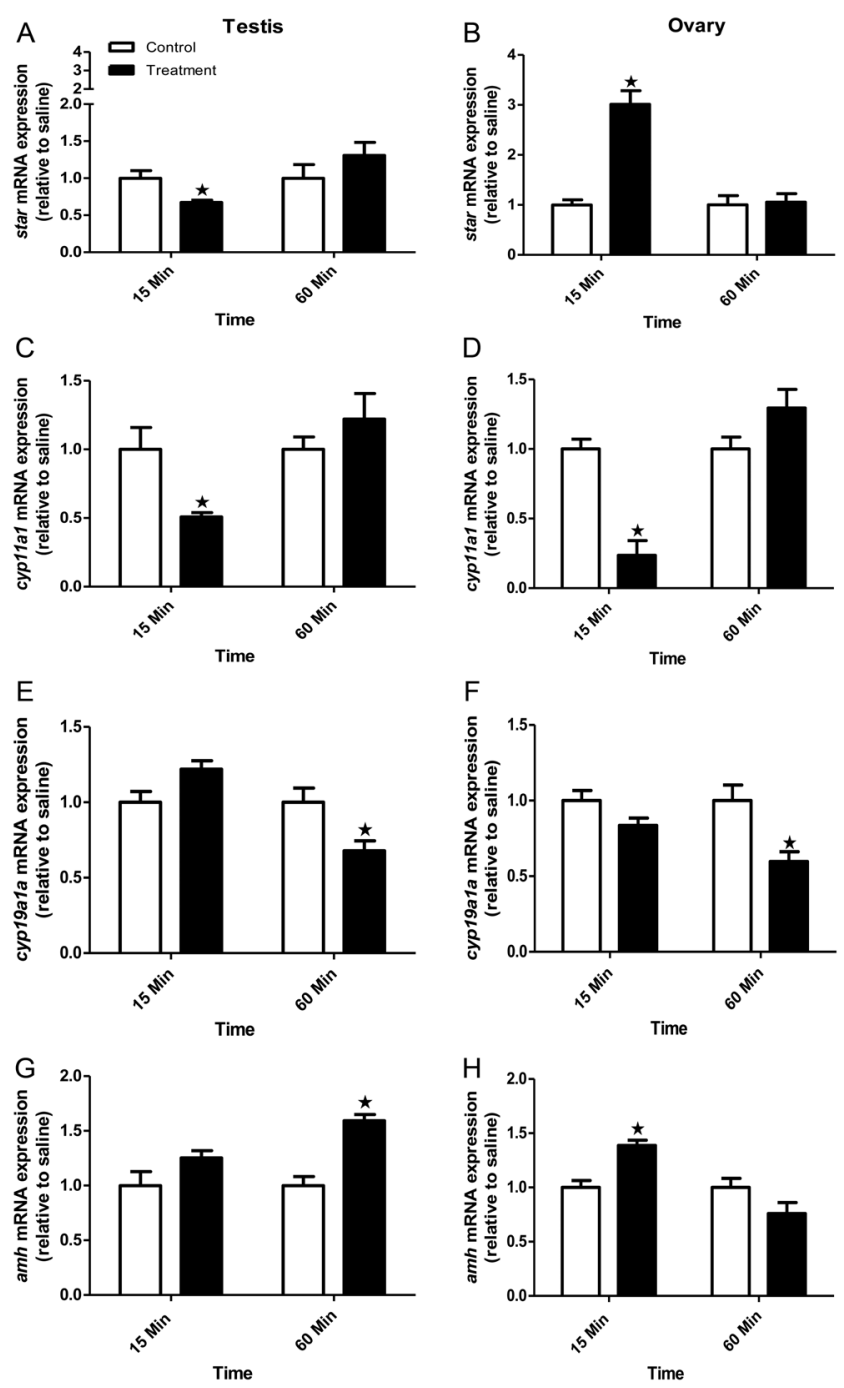

Figure 5 mRNA expression profile of genes involved in the sex steroidogenic pathway in the testis (left panel) and ovary (right panel) of goldfish post-nesfatin-1 administration (A-H). Nesfatin-1 suppresses the expression of star mRNA in the testis (A) and elevates it in the ovary (B) of goldfish. A significant decrease in cyp11a1 (at $15 \mathrm{~min}$ ) and cyp 19a1a (at $60 \mathrm{~min}$ ) was found in the testis (C \& E) and ovary (D \& F) of goldfish. A significant increase in the mRNA expression of amh was observed in the testis (at $60 \mathrm{~min}$ ) and ovary (at $15 \mathrm{~min}$ ) of goldfish post-nesfatin-1 administration $(\mathrm{G}, \mathrm{H})$. Data obtained by RT-qPCR are represented as mean + S.E.M. ( $n=6$ fish/ group). Student's t-test was used for statistical analysis, and the level of significance was set at $P<0.05$. Asterisks denote significant differences between control and treated groups.

\section{Nesfatin-1 influenced the expression of genes involved in the sex steroidogenesis in the gonads of goldfish}

In the testis, a significant reduction in star mRNA expression was observed (Fig. 5A) 15 min post nesfastin-1 injection. However, in the ovary, a significant increase in mRNA expression was observed at 15 min postnesfatin-1 administration (Fig. 5B). Cytochrome P450 family 11 subfamily A member 1 (cyp11a1), also called cholesterol side-chain cleavage enzyme (p450ssc), expression was significantly downregulated in both testis and ovary of goldfish at 15 min post-nesfatin-1 administration (Fig. 5C and D). Cytochrome P450 family 19 subfamily A member 1 (aromatase, cyp 19a1a) mRNA expression was significantly downregulated at $60 \mathrm{~min}$ post-nesfatin-1 administration in the gonads of goldfish (Fig. 5E and F). In the testis, we observed a significant increase in amh mRNA expression at $60 \mathrm{~min}$ postinjection (Fig. 5G). However, in the ovary, amh mRNA expression was upregulated only during the 15-min post-nesfatin-1-injection (Fig. 5H) time point.

\section{Nesfatin-1 downregulated the circulating levels of sex steroids in both male and female goldfish}

We found a significant decrease in circulating testosterone (T) levels in the male treatment group at 60 min post-nesfatin-1 administration (Fig. 6A). Similarly, a significant decrease in plasma estradiol (E) levels in females was detected at $60 \mathrm{~min}$ post-nesfatin-1 administration (Fig. 6B).

\section{Discussion}

Nesfatin-1 was originally identified as a metabolic regulator involved in feed intake regulation and energy homeostasis (Oh-l et al. 2006, Gonzalez et al. 2010). Recent evidences indicate that nesfatin-1 also has sex-specific regulatory roles in metabolism and reproduction (Bloem et al. 2012, Hofmann et al. 2015, Schalla \& Stengel 2018). As an extension of our own previous findings (Gonzalez et al. 2012a) on nesfatin-1 and reproduction, this research explored how nesfatin-1 affects goldfish HPG axis. In goldfish, two Gnrh isoforms are expressed in the brain, namely sGnrh and cGnrh-II, and both are shown to stimulate gonadotropin release in goldfish (Peter et al. 1985, Kim et al. 1995). We found that nesfatin-1 suppresses the expression of
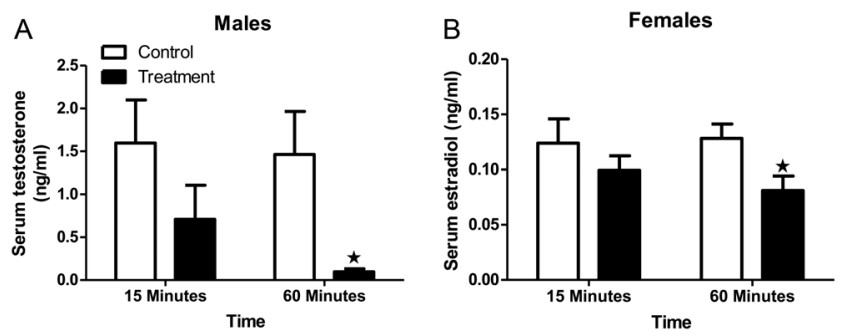

Figure 6 Serum testosterone and estradiol profiles in male and female goldfish post-nesfatin-1 administration. A significant decrease in serum levels of testosterone was observed in male fish group $60 \mathrm{~min}$ post-nesfatin-1 administration (A). A significant decrease in serum estradiol was observed in female fish groups at 60 min postnesfatin-1 administration (B). Data are represented as mean +S.E.M. ( $n=6$ fish/group). Student's $t$-test was used for statistical analysis, and the level of significance was set at $P<0.05$. Asterisks denote significant differences between control and treated groups. 
both sgnrh and cgnrh-II mRNAs in the brain of both male and female goldfish. This is in agreement with the earlier report by Gonzalez et al. 2012a, and adds on to the original findings to indicate that, in both sexes, nesfatin-1 applies the same effect on Gnrh. We observed a reduction in the expression of Gnrh mRNAs within 15 min of nesfatin-1 administration, and this suggests that the action of nesfatin- 1 in the brain after acute administration is very rapid. It was documented in mammalian studies that nesfatin-1 administered peripherally reach the brain roughly in $10 \mathrm{~min}$ and can cross the blood brain barrier in a non-saturable way (Pan et al. 2007, Price et al. 2007). Our results suggest a similar kind of mechanism is in operation in fish as well. The doses and time-points chosen here were previously validated in goldfish and are known to affect feeding and reproductive hormones (Gonzalez et al. 2010, 2012a). The circulating levels of nesfatin-1 in goldfish is $2.52 \pm 0.26 \mathrm{ng} / \mathrm{mL}$ (Gonzalez et al. 2010). Based on this, the dose tested here appears to be supraphysiological or pharmacological. A significant reduction in the expression of gpr54a (kiss 1 receptor) mRNA expression in the hypothalamus of both male and female treatment groups at 15 min post-injection was observed. The role of nesfatin-1 in the expression of the kisspeptin system is not addressed in any teleosts so far. Incubation of murine hypothalamic (GT1-7) and pituitary (L $\beta \mathrm{T} 2)$ cell lines with nesfatin-1 increased the expression of gpr54a (Hatef \& Unniappan 2017). This study points to the ability of nesfatin-1 to act directly on both hypothalamic neurons and gonadotrophs derived from mice. Direct action of nesfatin-1 on fish hypothalamic neurons and pituitary gonadotrophs is yet to be determined. In mammals, nesfatin- 1 is generally considered as a positive regulator of reproduction (García-Galiano et al. 2010, 2012). However, intracerebroventricular (ICV) injection of nesfatin-1 decreases the expression of gnrh and kisspeptin in male rats (Gao et al. 2016). This suggests that the sex of the animal and mode of administration might affect the action of nesfatin- 1 . We also found that nesfatin- 1 suppresses the expression of brain aromatase (cyp19a1b) mRNA in the hypothalamus of male and female goldfish. Aromatase plays an important role in the sexual behavior in both male and female goldfish (Lord et al. 2009). Reduction in brain aromatase transcript suggests possible role of nesfatin-1 in goldfish sexual behavior. Nesfatin-1 effects on feeding, anxiety and depression-like behaviors have not not been documented in fish and mammals (Lin et al. 2014, Kühne et al. 2018). A role for nesfatin-1 in sexual behavior has not yet been documented, but the results provided here raises a possible role for nesfatin- 1 on sex behavior. In addition, it was reported that nesfatin-1 influence the genes involved in sex steroidogenesis in males rats (Gao et al. 2016), which suggest regulatory mechanisam of nesfatin-1 in vertebrates conserved across species. Overall, our data provides additional support to the notion that nesfatin-1 negatively influences hypothalamic hormones in fish.

In the pituitary, $f s h \beta$, Ih $\beta$ and gpr $54 a$ mRNA expression was decreased after nesfatin-1 administration. However, we did not observe any significant changes in kiss 1 mRNA expression, which is similar to what we observed in the hypothalamus. It was reported earlier by immunohistochemical analysis that nesfatin- 1 is abundantly expressed in the pituitary (Gonzalez et al. 2012a), suggesting its possible regulatory role in pituitary functions. The suppression of gonadotropin mRNA expression, the key regulators of vertebrate reproduction (Gharib et al. 1990, Zhang et al. 2015), is additional evidence for the negative effect of nesfatin- 1 on goldfish reproduction. More evidence for the negative influence of nesfatin- 1 was observed in the gonads of goldfish. In both sexes, Ih and fsh receptor mRNA expressions were suppressed after nesfatin-1 administration. Contrary to what was observed in the hypothalamus and pituitary, we found an increase in both kiss 1 and gpr54a mRNA expression in both male and female gonads. Our results from gonadal mRNA expression suggest that nesfatin-1 has tissue-specific effects on goldfish reproduction. Further studies are needed to confirm whether elevated kiss 1 and gpr54a is a feedback response or not. While most of the stimulatory hormones were downregulated, an opposite (upregulation) effect was found in the case of inhibitory hormones. A significant increase in both gnih and gnihr mRNA expression, which is a potent inhibitor of reproduction in vertebrates (Tsutsui et al. 2010), was found in the gonads of goldfish. This possibly is an additional mechanism by which nesfatin-1 exerts its negative effects on goldfish reproduction. Together, these results suggest that nesfatin- 1 influences all three components of the HPG axis to modulate reproductive hormones.

In addition to the overall negative effects of nesfatin-1 on HPG genes that promote reproduction, we observed the influence of nesfatin-1 on genes involved in sex steroidogenesis. A reduction in star (in testis only), cyp11a1, and cyp19a1a mRNA expression was found after nesfatin-1 administration. This suggests that nesfatin-1 effects on sex steroidogenesis is limited not only to mammals as previously described (Gao et al. 2016), but a similar regulatory pattern is in operation in fish as well. We also found an increase in the expression of amh, a potent inhibitor of sex steroidogenesis in vertebrates including fish (Rodríguez-Marí et al. 2005, Halm et al. 2007, Pala et al. 2008, Pfennig et al. 2015, Lambeth et al. 2016, Xu et al. 2019). This furnishes additional support for the suppressive effect of nesfatin-1 on goldfish reproduction. A sex-specific expression pattern of ar was found in nesfatin-1 treated fish. In the final study, we determined whether the changes in mRNA expression would eventually result in alterations in hormone levels. In fact, a significant reduction in serum $T$ and $E$ levels was found at 60 min after nesfatin-1 
injection. These results, for the first time, show that gonadal sex steroids are targets of nesfatin- 1 . Nesfatin-1 influences male and female sex steroidogenic enzymes in a time-dependant manner. However, it is unclear whether nesfatin-1 affects gonadal steroid synthesis, secretion and/or clearance, or all of these processes that determine circulating levels. A significant decrease in star and cyp11a1 found in male goldfish possibly contributes to the reduction in circulating testosterone levels. It is possible that elevated amh is another factor affecting circulating testosterone levels in male fish treated with nesfatin-1. In the ovary, significant decreases found in both cyp11a1 and cyp19a1a likely mediate the negative effects of nesfatin-1 on circulating estradiol levels. The increase in star mRNA at $15 \mathrm{~min}$ post-injection in the ovary is possibly a feedback response to induce cholesterol uptake and thereby increase substrate availability. The mechanism of action of nesfatin-1 in causing these steroidogenic responses requires additional studies. For example, we currently do not know the significance of nesfatin-1 suppression of gonadal cyp19a1a and cyp19a1b (brain aromatase) expression in male fish and its implications in male reproductive physiology. Since the circulating levels of estradiol in male fish was not measured, we are unsure to what extend the changes in aromatase (cyp19a1a) gene expression will reflect in circulating estradiol levels. During development, majority of fish species exhibit gonadal expression of aromatase in males (reduced expression) and females (elevated expression) (Guiguen et al. 2010). Additional studies to understand the physiological relevance of such patterns of gonadal aromatase expression is essential. In addition, we did not quantify cyp17a1 expression in the gonads of goldfish due to the lack of sequence information (to design primers). Further studies are required to clearly understand the exact processes in steroid production and secretion that are influenced by nesfatin- 1 in both male and female fish. Together, our results indicate nesfatin-1 influence all tissues of the HPG axis and influence many critical hormonal regulators of fish reproduction.

In conclusion, we reconfirmed some of the acute effects of nesfatin-1 on goldfish reproduction (Gonzalez et al. 2012a) in both males and females separately. In addition, we extended these results into additional brain and pituitary hormones including kisspeptin and gnih and gonadal steroids. Most of the in vivo effects of nesfatin-1 found in this study ceased within $60 \mathrm{~min}$ of administration. Additional research is necessary to determine the chronic effects of nesfatin-1 on fish reproductive hormones and reproduction. The novelty of this research lies in the findings of nesfatin- 1 effects on kisspeptin, gnih and steroidogenic enzymes, and hormone receptors, as we all circulating sex steroids. Our results suggest sex- and tissue-specific effects for nesfatin-1 in goldfish. Nesfatin-1 in goldfish is a suppressor of pro-reproductive hormones, while it promotes inhibitors of reproduction. Additional studies are required to understand the actions and mechanism of actions of nesfatin- 1 on steroidogenic cells. While we only studied mRNA expression in tissues, the measurement of sex steroids provided a meaningful endpoint reflective of reproductive outcomes in fish. The results provided here enabled us to reach an overall conclusion that, by acting at all levels of the HPG axis, nesfatin- 1 acts as a suppressor of reproduction in fish.

\section{Declaration of interest}

The authors declare that there is no conflict of interest that could be perceived as prejudicing the impartiality of the research reported.

\section{Funding}

This work was supported by a Discovery Grant from the Natural Sciences and Engineering Research Council (NSERC) of Canada, an Establishment grant from Saskatchewan Health Research Foundation (SHRF), John R. Evans Leaders Fund from the Canada Foundation for Innovation, and the University of Saskatchewan Centennial Enhancement Chair in Comparative Endocrinology to SU. JJR is a recipient of WCVM-CGPS PhD Scholarship.

\section{Author contribution statement}

JJR planned and conducted the studies, analyzed and interpreted data, prepared the manuscript draft and revised it for submission. SU provided the original idea and funding, helped in the planning, designing of experiments and assisted in tissue sampling, data analysis and interpretation, manuscript preparation and revisions.

\section{Acknowledgements}

The authors thank the animal order desk and the WCVM animal care unit staff for their assistance in the procurement of fish and their care. The authors sincerely thank Susan Cook and Kim Tran (Endocrine Laboratory, Department of Veterinary Biomedical Sciences, WCVM) for their help and support to conduct ELISA studies.

\section{References}

Bertucci JI, Blanco AM, Canosa LF \& Unniappan S 2016 Estradiol and testosterone modulate the tissue-specific expression of ghrelin, ghs-r, goat and nucb2 in goldfish. General and Comparative Endocrinology 228 17-23. (https://doi.org/10.1016/j.ygcen.2016.01.006)

Blanco AM, Gómez-Boronat M, Alonso-Gómez ÁL, Yufa R, Unniappan S, Delgado MJ \& Valenciano Al 2017 Characterization of ghrelin O-acyltransferase (GOAT) in goldfish (Carassius auratus). PLoS One 12 e0171874. (https://doi.org/10.1371/journal.pone.0171874)

Bloem B, Xu L, Morava E, Faludi G, Palkovits M, Roubos EW \& Kozicz T 2012 Sex-specific differences in the dynamics of cocaine- and amphetamine-regulated transcript and nesfatin- 1 expressions in the 
midbrain of depressed suicide victims vs. controls. Neuropharmacology 62 297-303. (https://doi.org/10.1016/j.neuropharm.2011.07.023)

Caldwell LK, Pierce AL, Riley LG, Duncan CA \& Nagler JJ 2014 Plasma nesfatin-1 is not affected by long-term food restriction and does not predict rematuration among iteroparous female rainbow trout (Oncorhynchus mykiss). PLoS One 9 e85700. (https://doi.org/10.1371/ journal.pone.0085700)

Evans J \& Anderson GM 2012 Balancing ovulation and anovulation: integration of the reproductive and energy balance axes by neuropeptides. Human Reproduction Update 18 313-332. (https://doi. org/10.1093/humupd/dms004)

Gao X, Zhang K, Song M, Li X, Luo L, Tian Y, Zhang Y, Li Y, Zhang X, Ling $Y$ et al. 2016 Role of Nesfatin-1 in the reproductive axis of male rat. Scientific Reports 6 32877. (https://doi.org/10.1038/srep32877)

García-Galiano D, Navarro VM, Roa J, Ruiz-Pino F, Sánchez-Garrido MA, Pineda R, Castellano JM, Romero M, Aguilar E, Gaytán F et al. 2010 The anorexigenic neuropeptide, nesfatin-1, is indispensable for normal puberty onset in the female rat. Journal of Neuroscience 30 7783-7792. (https://doi.org/10.1523/JNEUROSCI.5828-09.2010)

García-Galiano D, Pineda R, Ilhan T, Castellano JM, Ruiz-Pino F, SánchezGarrido MA, Vazquez MJ, Sangiao-Alvarellos S, Romero-Ruiz A, Pinilla L et al. 2012 Cellular distribution, regulated expression, and functional role of the anorexigenic peptide, NUCB2/Nesfatin-1, in the testis. Endocrinology 153 1959-1971. (https://doi.org/10.1210/en.20112032)

Gharib SD, Wierman ME, Shupnik MA \& Chin WW 1990 Molecular biology of the pituitary gonadotropins. Endocrine Reviews 11 177-199. (https://doi.org/10.1210/edrv-11-1-177)

Gonzalez R, Kerbel B, Chun A \& Unniappan S 2010 Molecular, cellular and physiological evidences for the anorexigenic actions of nesfatin-1 in goldfish. PLoS One 5 e15201. (https://doi.org/10.1371/journal. pone.0015201)

Gonzalez R, Mohan H \& Unniappan S 2012b Nucleobindins: bioactive precursor proteins encoding putative endocrine factors? General and Comparative Endocrinology 176 341-346. (https://doi.org/10.1016/j. ygcen.2011.11.021)

Gonzalez R, Shepperd E, Thiruppugazh V, Lohan S, Grey CL, Chang JP \& Unniappan S 2012a Nesfatin-1 regulates the hypothalamo-pituitaryovarian axis of fish. Biology of Reproduction 87 84. (https://doi. org/10.1095/biolreprod.112.099630)

Guiguen Y, Fostier A, Piferrer F \& Chang CF 2010 Ovarian aromatase and estrogens: a pivotal role for gonadal sex differentiation and sex change in fish. General and Comparative Endocrinology 165 352-366. (https:// doi.org/10.1016/j.ygcen.2009.03.002)

Halm S, Rocha A, Miura T, Prat F \& Zanuy S 2007 Anti-Müllerian hormone $(\mathrm{AMH} / \mathrm{AMH})$ in the European sea bass: its gene structure, regulatory elements, and the expression of alternatively-spliced isoforms. Gene $\mathbf{3 8 8}$ 148-158. (https://doi.org/10.1016/j.gene.2006.10.018)

Hatef A, Shajan S \& Unniappan S 2015 Nutrient status modulates the expression of nesfatin-1 encoding nucleobindin 2A and 2B mRNAs in zebrafish gut, liver and brain. General and Comparative Endocrinology 215 51-60. (https://doi.org/10.1016/j.ygcen.2014.09.009)

Hatef A \& Unniappan S 2017 Gonadotropin-releasing hormone, kisspeptin, and gonadal steroids directly modulate nucleobindin-2/nesfatin-1 in murine hypothalamic gonadotropin-releasing hormone neurons and gonadotropes. Biology of Reproduction 96 635-651. (https://doi. org/10.1095/biolreprod.116.146621)

Hill JW, Elmquist JK \& Elias CF 2008 Hypothalamic pathways linking energy balance and reproduction. American Journal of Physiology: Endocrinology and Metabolism 294 E827-E832. (https://doi. org/10.1152/ajpendo.00670.2007)

Hofmann T, Elbelt U, Ahnis A, Rose M, Klapp BF \& Stengel A 2015 Sexspecific regulation of NUCB2/nesfatin-1: differential implication in anxiety in obese men and women. Psychoneuroendocrinology 60 130-137. (https://doi.org/10.1016/j.psyneuen.2015.06.014)

Kim MH, Oka Y, Amano M, Kobayashi M, Okuzawa K, Hasegawa Y, Kawashima S, Suzuki Y \& Aida K 1995 Immunocytochemical localization of sGnRH and cGnRH-II in the brain of goldfish, Carassius auratus. Journal of Comparative Neurology 356 72-82. (https://doi.org/10.1002/ cne.903560105)

Kühne SG, Schalla MA, Friedrich T, Kobelt P, Goebel-Stengel M, Long M, Rivalan M, Winter Y, Rose M \& Stengel A 2018 Nesfatin-130-59 injected intracerebroventricularly increases anxiety, depression-like behavior, and anhedonia in normal weight rats. Nutrients 10 1889. (https://doi. org/10.3390/nu10121889)

Lambeth LS, Morris K, Ayers KL, Wise TG, O'Neil T, Wilson S, Cao Y, Sinclair AH, Cutting AD, Doran TJ et al. 2016 Overexpression of antiMüllerian hormone disrupts gonadal sex differentiation, blocks sex hormone synthesis, and supports cell autonomous sex development in the chicken. Endocrinology 157 1258-1275. (https://doi.org/10.1210/ en.2015-1571)

Lin F, Zhou C, Chen H, Wu H, Xin Z, Liu J, Gao Y, Yuan D, Wang T, Wei R et al. 2014 Molecular characterization, tissue distribution and feeding related changes of NUCB2A/nesfatin-1 in Ya-fish (Schizothorax prenanti). Gene 536 238-246. (https://doi.org/10.1016/j.gene.2013.12.031)

Livak KJ \& Schmittgen TD 2001 Analysis of relative gene expression data using real-time quantitative PCR and the 2(-Delta Delta C(T)) Method. Methods 25 402-408. (https://doi.org/10.1006/meth.2001.1262)

Lord LD, Bond J \& Thompson RR 2009 Rapid steroid influences on visually guided sexual behavior in male goldfish. Hormones and Behavior $\mathbf{5 6}$ 519-526. (https://doi.org/10.1016/j.yhbeh.2009.09.002)

Mortazavi S, Gonzalez R, Ceddia R \& Unniappan S 2015 Longterm infusion of nesfatin-1 causes a sustained regulation of wholebody energy homeostasis of male Fischer 344 rats. Frontiers in Cell and Developmental Biology 3 22. (https://doi.org/10.3389/fcell. 2015.00022)

Oh S, Shimizu H, Satoh T, Okada S, Adachi S, Inoue K, Eguchi H, Yamamoto M, Imaki T, Hashimoto K et al. 2006 Identification of nesfatin-1 as a satiety molecule in the hypothalamus. Nature $\mathbf{4 4 3}$ 709-712. (https://doi.org/10.1038/nature05162)

Pala I, Klüver N, Thorsteinsdóttir S, Schartl M \& Coelho MM 2008 Expression pattern of anti-Müllerian hormone (amh) in the hybrid fish complex of Squalius Alburnoides. Gene 410 249-258. (https://doi. org/10.1016/j.gene.2007.12.018)

Pan W, Hsuchou H \& Kastin AJ 2007 Nesfatin-1 crosses the bloodbrain barrier without saturation. Peptides 28 2223-2228. (https://doi. org/10.1016/j.peptides.2007.09.005)

Peter RE, Nahorniak CS, Sokolowska M, Chang JP, Rivier JE, Vale WW, King JA \& Millar RP 1985 Structure-activity relationships of mammalian, chicken, and salmon gonadotropin releasing hormones in vivo in goldfish. General and Comparative Endocrinology 58 231-242. (https:// doi.org/10.1016/0016-6480(85)90339-9)

Pfennig F, Standke A \& Gutzeit HO 2015 The role of Amh signaling in teleost fish - multiple functions not restricted to the gonads. General and Comparative Endocrinology 223 87-107. (https://doi.org/10.1016/j. ygcen.2015.09.025)

Price TO, Samson WK, Niehoff ML \& Banks WA 2007 Permeability of the blood-brain barrier to a novel satiety molecule nesfatin-1. Peptides $\mathbf{2 8}$ 2372-2381. (https://doi.org/10.1016/j.peptides.2007.10.008)

Rajeswari JJ, Hatef A, Golshan M, Alavi SMH \& Unniappan S 2019 Metabolic stress leads to divergent changes in the ghrelinergic system in goldfish (Carassius auratus) gonads. Comparative Biochemistry and Physiology: Part A, Molecular \& Integrative Physiology 235 112-120. (https://doi.org/10.1016/j.cbpa.2019.05.027)

Rodríguez-Marí A, Yan YL, BreMiller RA, Wilson C, Cañestro C \& Postlethwait JH 2005 Characterization and expression pattern of zebrafish anti-Müllerian hormone (amh) relative to sox9a, sox9b, and cyp19a1a, during gonad development. Gene Expression Patterns 5 655-667. (https://doi.org/10.1016/j.modgep.2005.02.008)

Scaramuzzi RJ, Campbell BK, Downing JA, Kendall NR, Khalid M, MuñozGutiérrez M \& Somchit A 2006 A review of the effects of supplementary nutrition in the ewe on the concentrations of reproductive and metabolic hormones and the mechanisms that regulate folliculogenesis and ovulation rate. Reproduction, Nutrition, Development 46 339-354. (https://doi.org/10.1051/rnd:2006016)

Schalla MA \& Stengel A 2018 Current understanding of the role of Nesfatin-1. Journal of the Endocrine Society 2 1188-1206. (https://doi. org/10.1210/js.2018-00246)

Schneider JE 2004 Energy balance and reproduction. Physiology \& Behavior 81 289-317. (https://doi.org/10.1016/j.physbeh.2004.02.007)

Tsutsui K, Bentley GE, Bedecarrats G, Osugi T, Ubuka T \& Kriegsfeld LJ 2010 Gonadotropin-inhibitory hormone $(\mathrm{GnlH})$ and its control of central and peripheral reproductive function. Frontiers in Neuroendocrinology 31 284-295. (https://doi.org/10.1016/j.yfrne.2010.03.001) 
Unniappan S 2010 Ghrelin: an emerging player in the regulation of reproduction in non-mammalian vertebrates. General and Comparative Endocrinology 167 340-343. (https://doi.org/10.1016/j. ygcen.2009.12.003)

Wernecke K, Lamprecht I, Jöhren O, Lehnert H \& Schulz C 2014 Nesfatin-1 increases energy expenditure and reduces food intake in rats. Obesity 22 1662-1668. (https://doi.org/10.1002/oby.20736)

Xu HY, Zhang HX, Xiao Z, Qiao J \& Li R 2019 Regulation of anti-Müllerian hormone $(\mathrm{AMH})$ in males and the associations of serum $\mathrm{AMH}$ with the disorders of male fertility. Asian Journal of Andrology 21 109-114. (https://doi.org/10.4103/aja.aja_83_18)
Zhang Z, Zhu B \& Ge W 2015 Genetic analysis of zebrafish gonadotropin (FSH and LH) functions by TALEN-mediated gene disruption. Molecular Endocrinology 29 76-98. (https://doi.org/10.1210/me.2014-1256)

Received 4 February 2020

First decision 4 May 2020

Revised manuscript received 19 June 2020

Accepted 25 June 2020 